\title{
Isolation and identification of microorganisms in acne patients
}

\begin{abstract}
Niyan Innam Muhammed Yousif *
Rassool A. Dabbagh *

\section{Abstract}

Background and objective: Acne is a follicular skin disease most frequently occurring during the adolescent or the teenage years of a person's life. It has been found that around $85 \%$ of teenagers suffer from this skin disorder worldwide. However, acne is not only restricted to teenagers but in many cases continues well into adulthood. This study aimed to examine the prevalence of acne in relation to age in Erbil City, and isolation and identification of microorganisms in acne patients.

Methods: Specimens were collected from inflamed and discharging pus from 160 acne patients (74 male, 86 female) attending the Department of Dermatology in Rizgari Teaching Hospital in Erbil city. The cultures were examined using the Vitek-2 compact system.

Results: Among 160 samples taken, 150 (99\%) were culture positive. From there 70 $(46.6 \%)$ were male and $80(53.3 \%)$ were female. Only ten $(6.25 \%)$ samples revealed no growth. The highest prevalence of acne was $32(20.0 \%)$ at age group (15-17) years of both genders. The most frequent etiological agent isolated (aerobically) bacteria from acne patients was Staphylococcus epidermidis (27.08\%), and the most common anaerobic pathogen bacteria species were Propionibacterium acnes, 25 (13.02\%), while among fungi Candida albicans was the most common fungi representing nine $(64.29 \%)$ isolates.

Conclusion: Gram-positive bacteria were the most common microorganisms involved in acne infection. There are variations in the incidence of acne infection in relation to sex, age, and socioeconomic level.
\end{abstract}

Keywords: Acne; Skin flora; Vitek 2 compact system.

\section{Introduction}

Acne vulgaris is known medically as the most common skin disorder. It is an inflammatory disorder occurring mostly on the face, but it can also extend to the areas of the neck, chest, and the back. ${ }^{1}$ All acne is a disorder of the pilosebaceous unit. The greatest number of pilosebaceous units are found on the face, upper neck, and chest $^{2}$. Sebum is a substance produced by sebaceous glands during adolescence. These glands enlarge and produce more sebum under the influence of hormones, which is called androgens. The sebum production begins to decrease, after about age 20 years. $^{3}$ Open or closed comedones (both blackheads and whiteheads), are characterization of acne.
The severity of acne is determined by the number, type and distribution of the lesions. ${ }^{4}$ The secretions of our sweat and sebaceous glands feed the acne bacteria, and this is a normal biological state, that occurs on the skin of every individual. ${ }^{5}$ Gram-positive cocci (Staphylococcus epidermidis and Micrococcus spp, corynebacteria and Propionibacterium spp) are the most common skin microbes found in the superficial layers of the epidermis and the upper parts of the hair follicles. These are considered to be communal, and are generally nonpathogenic although mutualistic and parasitic roles have been assigned to them. Propionibacterium acnes which are a normal inhabitant of the skin produce fatty acids that inhibit the growth

* Department of Microbiology, College of Medicine, Hawler Medical University, Erbil, Iraq. 
of fungi on the skin. ${ }^{6}$ But, when it becomes trapped inside the hair follicle, it may grow and cause inflammation and acne infection. $^{7}$ No study had been published in our region regarding identification of microorganisms in acne infection. Therefore, this study aimed to isolate and identify the microorganisms in acne patients.

\section{Methods}

\section{Sample collection}

This study was carried out during the period of September 2010 to March 2011. Samples were collected from 160 acne patients (74 male, 86 female) attending the Department of Dermatology in Rizgari Teaching Hospital in Erbil city. The age of patients ranged from 11 to 35 year. Full information was taken directly from the patients and formulated on the data sheet. Specimens were collected from inflamed and discharging pus of acne. Bacteriological loop or disposable sterile cotton swabs, and transport media used for this purpose. These swabs, or specimens, were immediately transported to the laboratory of graduate studies in the Department of Microbiology in the College of Medicine in Hawler Medical University and processed using bacterial cultures, fungi cultures, and isolation and identification of bacteria and fungi. For anaerobes, the samples were inoculated in thioglycolate broth incubated anaerobically at $37^{\circ} \mathrm{C}$ overnight for primary isolation. The specimens were inoculated on both blood agar and selective media. MacConkey agar, Nutrient agar, Muller Hinton agar, Nutrient broth, and DNase agar were used. Enriched and selective media are required for recovery of anaerobes, which should be freshly prepared or used within two weeks of preparation. Streaking method was used for the isolation of pure colonies. Pure colonies of gram-positive cocci were transferred and subcultured on blood agar. Gram negative bacteria were sub-cultured on nutrient agar. Anaerobes were sub-cultured on neomycin blood agar.
Sabouraud's dextrose agar, were used for fungi. This medium supports the growth of most fungi. Pure colonies were identified using morphological, biochemical, physiological characteristics. The newly redesigned colorimetric VITEK-2 Compact system with the updated advanced Expert System (AES) (bioMerieux, Marcy L'Etoile, France) was evaluated for its accuracy and rapidity to identify clinical isolates. Identification of anaerobic bacteria was by API 20A. Anaerobic conditions are prepared for anaerobic bacteria to grow (Candle jar and gas pages used for this purpose). Overall, the VITEK-2 gave $95.8 \%$ of compatibility with the reference API strips (bioMerieux) in the identifications (IDs) of Gram-positive cocci (GPC), Gram-negative rods (GNR), and yeasts. The accuracy was finally estimated at $98.3 \%$ through additional confirmatory tests. Also, $>90 \%$ of IDs of GPC and GNR were obtained within seven hours. This study was carried on patients under specialist supervision. Only the investigators have dealt with the results. No harm was done to the participants with only swabs were taken and a verbal consent was taken from the participants. The study was approved by the Research Ethics Committee of the College of Medicine of Hawler Medical University. Analysis of data was performed by using the Excel program. Results are expressed as a percentage (\%). The correlation analysis was done with the statistical package for the social sciences program.

\section{Results}

As can be seen in Table 1, swabs were collected from 160 patients with acne; 86 female and 74 male. The ratio of female to male was 1.16: 1 . According to the type of growth culture $150 \quad(93.75 \%)$ produced positive culture. Whereas 10 (6.25\%) produced negative cultures. Out of the positive, $70(46.6 \%)$ were male and 80 $(53.3 \%)$ were female. Table 2 shows that the highest proportion of patients were in 
the age group $15-17$ years $(20.0 \%)$, and the lowest proportion of patients occurred at age group less than 12 years (1.9\%). The mean age of patients was 21.13 years. Table 3 and Figure 1 show that the highest percent of the isolates belonged to the genus Staphylococcus epidermidis representing $52(27.08 \%)$ isolates, while Enterococcus faceium represented the lowest percent of isolates $(0.52 \%)$. The most common anaerobic pathogen bacteria species were Propionibacterium acnes, 25 (13.02\%).

Table 1: Distribution of acne patients in relation to gender.

\begin{tabular}{lcccccc}
\hline \multirow{2}{*}{ Gender } & \multicolumn{2}{c}{ Positive Culture } & \multicolumn{2}{c}{ Negative Culture } & \multicolumn{2}{c}{ Total } \\
& No. & $(\%)$ & No. & $(\%)$ & No. & (\%) \\
\hline Male & 70 & $(46.66)$ & 4 & $(2.50)$ & 74 & $(48.25)$ \\
Female & 80 & $(53.33)$ & 6 & $(3.75)$ & 86 & $(56.75)$ \\
Total & 150 & $(99.9)$ & 10 & $(6.25)$ & 160 & $(100)$ \\
\hline
\end{tabular}

Table 2: Distribution of acne patients by age.

\begin{tabular}{lcc}
\hline Age Groups & No. & $\mathbf{( \% )}$ \\
\hline$<12$ & 3 & $(1.88)$ \\
$12-14$ & 24 & $(15.0)$ \\
$15-17$ & 32 & $(20.0)$ \\
$18-20$ & 26 & $(16.25)$ \\
$21-23$ & 17 & $(10.63)$ \\
$24-26$ & 20 & $(12.50)$ \\
$27-29$ & 16 & $(10.0)$ \\
$30-32$ & 12 & $(7.50)$ \\
$33-35$ & 10 & $(6.25)$ \\
Total & 160 & $(100)$ \\
\hline
\end{tabular}

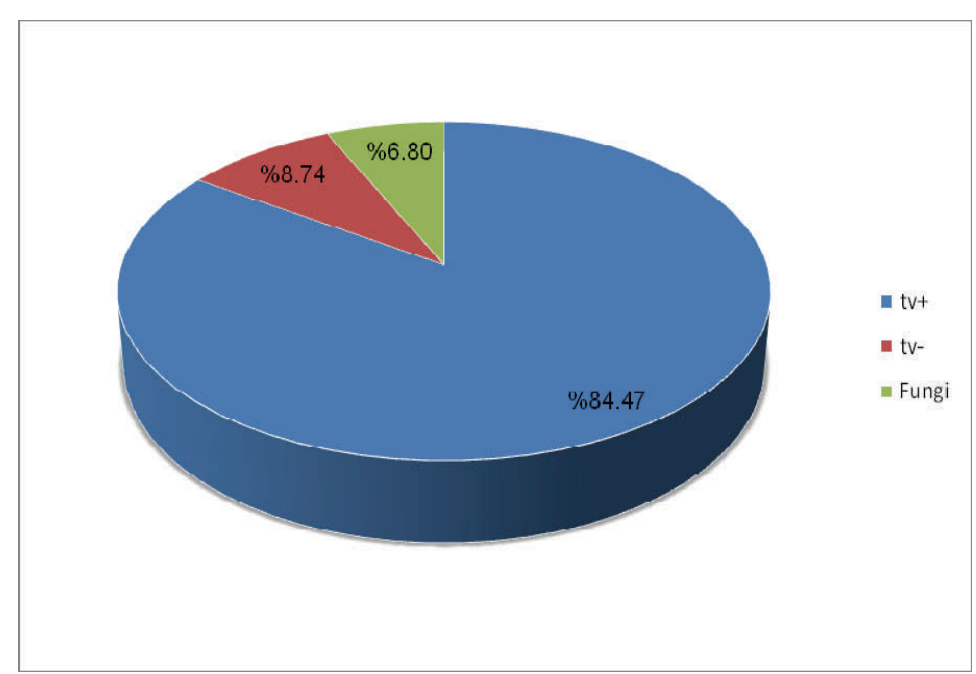

Figure 1: The total percentage of microorganisms isolated from patients with acne ( $+v e=$ Gram positive bacteria, $-\mathrm{ve}=$ Gram negative bacteria). 
Table 4 and Figure 1 show that the high percent of fungi isolate were Candida albicans (64.29\%). The lowest percent of fungi isolates were Pityrosporium spp. $(14.29 \%)$. The incidence of acne in relation to socioeconomic level was examined by asking the patients some questions during sample collection and labeled it in a data sheet.

Table 3: Identity and number of Isolated bacteria.

\begin{tabular}{lcc}
\hline Bacterial isolates & No. & (\%) \\
\hline S. epidermidis & 52 & $(27.08)$ \\
P.acnes & 25 & $(13.02)$ \\
Kocuria varians & 16 & $(8.33)$ \\
S. hominis & 11 & $(5.73)$ \\
Kocuria kristinae & 9 & $(4.69)$ \\
S. aureus & 7 & $(3.65)$ \\
S. warneri & 7 & $(3.65)$ \\
Acintobacter lowffi & 6 & $(3.13)$ \\
S. lentus & 6 & $(3.13)$ \\
Moraxella group & 6 & $(3.13)$ \\
Peptococcus niger & 6 & $(3.13)$ \\
S. haemolyticus & 4 & $(2.08)$ \\
S. capitis & 4 & $(2.08)$ \\
Granulocatella eligans & 4 & $(2.08)$ \\
Aerococcus viridans & 4 & $(2.08)$ \\
Leuconostoc mesenteroides & 3 & $(1.56)$ \\
Kocuria rosea & 3 & $(1.56)$ \\
S. intermedius & 3 & $(1.56)$ \\
Oligella ureolytica & 3 & $(1.56)$ \\
S. sciuri & 3 & $(1.56)$ \\
E. coli & 2 & $(1.04)$ \\
S. vitulinues & 2 & $(1.04)$ \\
S. chromogenes & 2 & $(1.04)$ \\
S. simlunis & 2 & $(1.04)$ \\
Dermococcus nishinomyiaensis & 1 & $(0.52)$ \\
Enterococcus faecium & 192 & $(0.52)$ \\
Total & & $(100)$ \\
\hline
\end{tabular}

Table 4: Percentage of fungi isolated from acne patients.

\begin{tabular}{lcc}
\hline Fungi isolate & No. of isolate & $(\%)$ \\
\hline Candida albicans & 9 & $(64.29)$ \\
Cryptococcus.albidus & 3 & $(21.43)$ \\
Pityrosporium spp & 2 & $(14.29)$ \\
Total & 14 & $(100)$ \\
\hline \hline
\end{tabular}


http://dx.doi.org/10.15218/zjms.2016.0028

Table 5 shows that the frequency of acne was higher among the patients with low socioeconomic level (50\%), and the lowest among patients with a high socioeconomic level $(14 \%)$, taking into consideration their education and hygiene.

\section{Discussion}

In our work, we studied 160 cases suspected to have acne. Among them, 150 $(93.75 \%)$ gave positive growth of bacteria and other organisms. This was in agreement with the findings of two other studies $^{8,9}$ that reported that $88 \%$ of the examined patients had positive acne cultures. However, there has been reports in the field that positive culture was in the range of $78 \%$. ${ }^{10}$ Lower percentages of the infections were reported by other investigators from Egypt who showed that only $11.88 \%$ patients had acnes. ${ }^{11}$ It is of interest to notice that negative cultures in our case may be due to many reasons such as technical errors. Other reasons for negative cultures could be due to viral infections that cannot be isolated by conventional methods used in this study and may need a special technique for their isolation. ${ }^{12}$ The results also showed that the percentage of infection in females $(46.2 \%)$ was higher than males $(30.2 \%)$. Our results are in agreement with findings of a study from America that found a higher prevalence of acne among females than males ( $72 \%$ females, $28 \%$ males). A study from Nigeria found that a large number of microorganisms were isolated from female patients $(65 \%)$ and $(35 \%)$ in males. ${ }^{13}$ The gender distribution was also similar to that reported by two other studies, ${ }^{14,15}$ that showed that the percentage of infection was higher in females compared to that of males. A study from Iraq found that acne infection was more in female than in male. $^{16}$ The results of the present study showed that the highest prevalence of acne occurred among the age group 15-17 years $(20 \%)$. This result is inconsistent with that reported by another study on the incidence of acne infections in America that stated that this age represents the age of hormonal imbalance. ${ }^{2}$ In our study, the lowest incidence of acne occurred among age groups $<12$ years $(1.9 \%)$, this result is in agreement with that reported by another study that showed that the prevalence of acne increase with age. ${ }^{4}$ This result disagrees with those reported by another study who found that the low percent of infections occurred at age 30 or above, because the acne, increased gradually with increasing age, and the prepubertal acne is associated with an excess of androgen. ${ }^{17}$ In the present study, various species of aerobic and facultative anaerobic bacteria were involved in causing acne infection. The results showed that the highest percent of the isolates belonged to the Staphylococcus epidermidis, followed by Propionibacterium acnes, Micrococci and Staphylococcus aureus. These results are in agreement with other studies. A study from India found that the rate of infection with Staphylococcus epidermidis was 53\%, while in Micrococci, Staph aureus, and Propionibacterium acnes were $45 \%, 41 \%$ and $33 \%$, respectively. ${ }^{18}$ A study from Britain showed that Staphylococcus epidermidis had been the most frequently isolated microorganism from the body surface. ${ }^{19}$ However, other studies have shown that Propionibacterium acnes as the most predominant bacteria causing acne infections. ${ }^{20-23}$ This bacteria play a major role in the pathogenesis of acne, and as an important opportunistic pathogen

Table 5: Socioeconomic level among 150 patients with acne.

\begin{tabular}{lcc}
\hline Socioeconomic Level & No. of Patients & (\%) \\
\hline High & 21 & $(14)$ \\
Medium & 54 & $(36)$ \\
Low & 75 & $(50)$ \\
Total & 150 & $(100)$ \\
\hline \hline
\end{tabular}


causing superficial skin infection because the microenvironment of the skin such as $(\mathrm{pH})$ is optimal condition for growth of Propionibacterium acnes, and this bacterium produces a variety of extracellular products, such as lipases, proteases, and chemotactic factors, which are responsible for the initiation and maintenance of the inflammatory response. In this study, we isolated Propionibacterium acnes in 25 of the patients which are representational $(13.02 \%)$. This is in agreement with two other studies ${ }^{24,25}$ who isolated pronpionibacterium acnes in a significant number of samples they studied. In this study, the total number of isolated yeast in acne patients were $14(6.79 \%)$ mostly Candida albicans. This is comparative to another study. ${ }^{26}$ Thus, we can postulate that these fungi, as normal flora of the skin, may cause acne whenever to have the chance to do so. As we know that Candida species are found as normal flora of the skin, they may cause acne and other infection. $^{7}$ Among other yeast isolated from patients with acne we studied, was Cryptococcus albidus. It is well known that is a saprophytic species of the Cryptococcus. It fails to grow above $35 \mathrm{c}$. It is clear that this organism is rarely isolated from the skin, and was reported by another study. ${ }^{27}$ It has been reported that these saprophytic species may initiate infection in immunocompromised individuals. ${ }^{28}$ It is also reported that the Cryptococcus species can cause a variety of skin lesions. ${ }^{29}$ A statistically significant difference was observed in the frequency of acne according to socioeconomic level. The highest number was in low level $(50 \%)$, followed by the medium level $(36 \%)$ and finally only $14 \%$ of the high level. Table 5 shows the incidence of acne infection among high, medium and low socioeconomic levels. Our result is in agreement with the findings of two other studies who reported that the lack of patient education, unhygienic conditions and the poor social status contribute towards the progression of the acne infection. $^{13,30}$ Our result disagrees with that done by another study who found no association between acne and socioeconomic level of patients. ${ }^{2}$ Females may get acne from their early onset of puberty. The menstrual cycle is characterized by the change in hormonal concentration and level of DHEAS. This may rise in pre-menstrual period and DHEAS which has been reported to facilitate initiation of acne. ${ }^{31}$

\section{Conclusions}

Females are more prone to develop an infection with acne, at age group 15-17 years. The most common pathogenic bacteria causing acne were Staphylococcus epidermidis and Propionibacterium acnes. The most common anaerobic pathogen bacteria species were Propionibacterium acnes. Among the fungi, Candida albicans was the most common etiological agent.

\section{Conflicts of interest}

The authors report no conflicts of interest.

\section{References}

1. Adityan B, Kumari R, Thappa DM. Scoring systems in acne vulgaris. Indian J Dermatol Venereol Leprol 2009; 75(3):323-6

2. Lasek RJ, Chren MM. Acne vulgaris and the quality of life of adult dermatology patients. Arch Dermatol 1998; 134:454-8.

3. Vexiau P, Husson C, Chivot M, Brerault JL, Fiet J, Julien R, et al. Androgen Excess in Women with Acne Alone Compared with Women with Acne and/or Hirsutism. J Invest Dermatol 1990; 94:279 $-328$.

4. Goulden V, Stables GI, Cunliffe WJ. Prevalence of facial acne in adults. J Am Acad Dermatol 1999; 41:577-80.

5. Cogen AL, Nizet V, Gallo RL. Skin microbiota: a source of disease or defence? $\mathrm{Br} \mathrm{J}$ Dermatol 2008; 158(3):442-55.

6. Johnson BA, Nunley JR. Topical therapy for acne vulgaris. How do you choose the best drug for each patient? Postgrad Med 2000; 107:69-70.

7. Roth RR, James WD. Microbial ecology of the skin. Annu Rev Microbiol 1988; 42:441-64

8. Ghodsi SZ, Orawa $\mathrm{H}$ and Zouboulis CC. Prevalence, severity, and severity risk factors of acne in high school pupils: A community-based study. J Invest Dermatol 2009; 129:2136-41.

9. Tan HH, Tan AW, Barkhman T, Yan XY and Zhu M. Community of acne vulgaris in aldoscents in Singapore. Br J Dermatol 2007; 157:547-51. 
10. Zandi S, Vares B, Abdollahi H. Determination of microbial agents of acne vulgaris and Propionibacterium acnes antibiotic resistance in patients referred to dermatology clinics in Kerman, Iran,. Jundishapur J Microbiol 2011; 4 (1):17-22

11. Al-Zoman YA, Facharizt A, Al-Asmari KA. Pattern of skin diseases at Riyadh Military Hospital. Egyptian Dermatol J 2008; 4(2):4.

12. Kriger JN, Kauser DL and Wenzel RP. Nosocomial infections cause infections in acne patients. Surgery 1993; 156:313-16.

13. Ikaraoha Cl, Taylor GL, Anetor JI, Ukaegbu QO, Nwobu GO. Demographic features, beliefs and socio-phychological impact of acne vulgaris among its sufferes in two towns in Nigeria. OJHAS 2009; 2:15-20

14. Hafez AM, Mahran MA, Mohammed AK, Mohammed RE, Darweesh MA, Aal AA. Quality of Life in Acne Vulgaris Patients. J Neurol Psychiat 2007; 44(1):301-12.

15. Yu SY, Cheng WY, Chen CW. Lifetime Course of Acne: A Retrospective Questionnaire Study in School Teachers. Dermatol Sinica 2008; 26: 10-15

16. Sharquie EK, Al-Hamdi IK, Adil A, Noaimi AA, Al-Battat AR. Scarring and None Scarring Facial Acne Vulgaris and the Frequency of associated Skin Diseases. J Med 2009; 8(4):13-33

17. Biswas S, Mondal KK, Saha I, Dutta NR, Lahiri KS. Clinico-epidemiological Features of Acne Vulgaris: A Tertiary Hospital-Based Study. Iran J Dermatol 2010; 13(2):37-41

18. Hassanzadeh $P$, Bahmani $M$, Mehrabani $D$. Bacterial resistance to antibiotics in acne vulgaris: an in vitro study. Indian J Dermatol 2008; 53(3):122-4.

19. Cunliffe WJ. Management of adult acne and acne variants. J Cutan Med Surg 1998; 2(3):7-13.

20. Nakatsuji T, Liu YT, Huang CP, Gallo RL, Huang CM. Antibodies elicited by inactivated Propionibacterium acnes-based vaccines exert protective immunity and attenuate the IL-8 production in human sebocytes: relevance to therapy for acne vulgaris. J Invest Dermatol 2008; 128:2451-7.

21. Biatecka A, Mak $M$, Biedroñ $R$, Bobek $M$, Kasprowicz A, Marcinkiewicz J. Different pro-inflammatory and immunogenic potentials of Propionibacterium acnes and Staphylococcus epidermidis: implication for chronic inflammatory acne. Arch Immunol Ther Exp 2005; 53:79-85

22. Nielsen ML, Raahave D, Stage JG, Justesen T. Anaerobic and aerobic skin bacteria before and after skin-disinfection with chlorhexidine: An experimental study in volunteers. J Clin Path 1975; 28:793-7.

23. Hatemi G, Bahar H, Uysal S, Mat C, Gogus F, Masatlioglu $S$, et al. The pustular skin lesions in Behc, et's syndrome are not sterile. Ann Rheum Dis 2004; 63:1450-2.
24. Bojar RA, Holland KT. Acne and Propionibacterium acnes. Clin Dermatol 2004; 22:375-9.

25. Gollnick H. Management of acne. A report of the global alliance to improve outcomes in acne. J Am Acad Dermatol 2003; 49:1-38.

26. Leeming JP, Holland KT, Cunliffe WJ. The microbial ecology of pilosebaceous units isolated from human skin. J Gen Microbiol 1984; 130:803-7.

27. Lacaz CS, Heins-Vaccari EM, HernandezArriagada GL, Martins EL, Prearo CL, Corim, SM et al. Primary cutaneous cryptococcosis due to Cryptococcus neoformans var. gattii serotype $B$, in an immunocompetent patient. Rev Inst Med Trop Sao Paulo 2002; 44(4):225-8.

28. Knoke M, Schwesinger G. One hundred years ago: the history of cryptococcosis in Greifswald. Medical mycology in the nineteenth century 1994; 37(8):229-33

29. Hazen KC, Howell SA. Candida, cryptococcus and other yeasts of medical importance. Manual of Clinical Microbiology 2007; 9:1762-88.

30. Zouboulis C, Eady A, Philpott M, Goldsmith L, Orfanos C, Cunliffe WJ. What is the pathogenesis of acne. Exp Dermatol 2005; 14:143-52.

31. Tallab TM. Beliefs, perceptions and psychological impact of acne vulgaris among patients in the Assir region of Saudi Arabia. West Afr J Med 2004; 23:85-7. 